\title{
Three Dimensional Finite Element Model of a Partially Continuous Joint
}

\author{
Marco Canales, $\mathrm{PhD}^{1}$, Ayman Okeil, $\mathrm{PhD}^{2}$ \\ ${ }^{1}$ Universidad Tecnológica Centroamericana, Honduras, marco.canales@unitec.edu.hn, \\ ${ }^{2}$ Louisiana State University, United States of America, aokeil@1su.edu
}

\begin{abstract}
A detailed three-dimensional finite element model of a bridge joint with link slab continuity was developed and subjected to the same loading conditions as a three-dimensional finite element model of a bridge joint with a continuity diaphragm.

Support conditions and material properties were homogenized between both models, and in order to determine the equivalent loading resulting from temperature gradient, a validated simplified line model was used. Displacements and rotations were then determined for the conditions in the detailed $3 D$ model using the simplified line model and were applied to the corresponding elements in the $3 D$ model.

Results showed a different stress distribution between both models. The higher continuity of the continuity diaphragm joint led to better stress distribution in the deck than the link slab joint in the partial continuity model. Bearing pads had different roles in both models and therefore different stress distribution and displacement field. The higher redundancy of the continuity diaphragm resulted in less influence of the bearing pads towards joint performance in the continuity diaphragm model than in the link slab model.

Keywords—Link slab, continuity diaphragm, bearing pads, finite element model.
\end{abstract}

\section{INTRODUCTION}

The use of jointless decks and continuous girder systems has been studied over several decades in a number of different approaches. Initially, simplified link slab joint models consisted of a two-noded isoparametric beam element for the girders and deck, and a two noded uniaxial spring element for the deck portion; i.e., the link slab [1]. This approach simplified the interaction between the girders and link slab, and limited the contribution from the link slab to its axial stiffness. The considerable stresses that could cause cracking in the immediacy of the joint were addressed by debonding link slab reinforcement for a certain length between the girder and the deck, which would allow a much greater length of the deck to distribute the resulting strain, and in turn reduce the stresses to which the deck is subjected [2]. This model was explored further through the development of a modified FEM model which would take into account the support stiffness to analyse the effects of the debonded length [3] [4].

Principles from these models are later put to the test with the analysis of in-service jointless bridges in West Virginia, finding that in fact the top of the concrete deck is subjected to high tensile stresses, and that temperature gradient is the major contributor to total stresses within the section [5] [6].

The model is further developed in order to obtain a practical design methodology for link slab elements, and it is determined that support conditions play an important role within the stress and strain interactions at the joint [7].

\footnotetext{
Digital Object Identifier (DOI):

http://dx.doi.org/10.18687/LACCEI2020.1.1.160

ISBN: 978-958-52071-4-1 ISSN: 2414-6390
}

Through a parametric study considering idealized support conditions for two span partially continuous bridges using link slabs, it is determined that bearing pad stiffness is closely linked to the continuity moment [8]. Further analysis of the impact of the link slab on overall bridge performance concludes there is a benefit in considering the partial continuity provided by a link slab through means of its extending the service life of the bridge [9].

The need to develop a better understanding of the behaviour of continuity joints led to a growing number of surveys, field studies, and structural health monitoring systems in recent years. The focus of these studies was mainly to evaluate different performance criteria for a fully continuous bridge [10-12]. These studies resulted in information and data that was used to develop three dimensional finite element models to better describe interactions within the joint $[13,14]$ and description of the force transfer mechanism involved [15].

\section{CONTINUITY}

When determining the nature of the model, as well as the intervening factors, it is important to consider the type of continuity that will be present at the joint. Overall, there are two overarching types of continuity, namely, partial continuity, and full continuity. Partial continuity is a broad concept that can include different degrees of continuity. There are multiple methods for achieving partial continuity in simple span girder bridges; one such method is to cast a continuous deck over the girders, or link slab. Due to the partial nature of the continuity provided by a link slab, the degree of continuity that this joint provides to the system will be greatly affected by the support conditions; i.e. stiffness. The partial continuity provided by a link slab will produce a displacement restraint on the top of the girders at the joint, but not at the bottom. This means the bottom of the girder is free to displace in any way that the supports do not restrict. By pouring concrete in between the girder ends in the form of a continuity diaphragm, it becomes possible to restrict any compressive displacement at the joint product of gravity loads. If positive moment reinforcement is in the form of hairpin bars or extended strands provided between the girder ends and the continuity diaphragm it also becomes possible to restrict tensile displacements that can take place at the joint due to temperature gradient and creep. With proper reinforcement design, cracking of the diaphragm can be controlled and a bridge segment can be considered to be fully continuous [16].

Several research projects have looked at the performance of different design alternatives, and in recent years the National Cooperative Highway Research Program sponsored 
Project 12-53 on positive moment continuity details for continuous prestressed concrete girder bridges. The findings from this project were published in NCHRP Report 519 [17]. From the results of Project 12-53, both design recommendations were adopted into the AASHTO LRFD Specifications [18], however the $180^{\circ}$-hook bar detailing was recommended over the $90^{\circ}$-hook due to possible interference with the formwork. However, concerns arose due to the asymmetrical reinforcement layout that results from the space restrictions. The general congestion in the diaphragm area also gave rise to concerns about how this type of joint can perform prompting additional research.

To address some of these concerns, as well as investigate the performance of this detailing under varying conditions several research projects were conducted [10]. This led to the development of a high-fidelity finite element (FE) joint model of a continuity diaphragm joint with hairpin $\left(180^{\circ}\right.$-hook) bars for positive reinforcement. This detailed model considers two important interactions: the cold joint between the cast in place diaphragm and the precast prestressed girders and the transfer of prestressing force [15].

In this study, the force transfer model used to investigate the behavior of full continuity joints with hairpin bars is modified to investigate a joint with deck-only continuity. This allows for the validation of years of research and theory through robust models that can describe interactions between structural components within partially continuous systems. It is through the formulation of a similar three-dimensional model that this work seeks to describe the effects of bearing pad support stiffness over the effectiveness of a link slab, as well as evaluate the effects that temperature gradient can have on the link slabs performance under these conditions.

\section{FINITE ELEMENT MODELING}

Partial continuity presents several challenges of its own when it comes to modeling. One of these challenges stems from the fact that the force transfer occurring at the joint does not follow in the conventional exchange of forces at a fully continuous joint. The simultaneous lack of full continuity and of structural independence makes it particularly difficult to simplify interactions at the joint.

By creating a line model like the one shown on Fig. 1 it became possible to represent important aspects of the interaction and obtain results that will be helpful in the design process. This type of simplified model, though it can do an acceptable job at representing the global behavior related to transfer of forces at the joint, fails at showing how this interaction will be affecting the sections and materials at the macro level. For example, the line model does not contemplate any types of geometric non-linearities caused by any cold joints or have any considerations for the effects of the prestress on the concrete girder in combination with temperature gradient or live load.

In the case of full continuity as is provided by the continuity diaphragm, the joint will be most affected by the discontinuity which can occur between adjacent surfaces as they separate under tensile forces while still being fully capable of handling large compressive forces. The AASHTOLRFD Bridge Design Specification calls for limiting positive moments on the continuity detail to be under 1.2 times the cracking moment, $1.2 M_{c r}$, [18]. The effects of temperature gradient on a positive continuity moment are equal to approximately $50 \%$ of the cracking moment [19], $M_{c r}$. Due to this value falling within the acceptable range in the specifications, the effects of material non-linearity due to large straining actions will not be considered. In this model, the principal source of non-linearity comes from the separation of adjacent surfaces of interacting materials.

For the case of partial continuity as is provided by a link slab, the importance of the material non-linearity does not manifest in the same way. There is no cast-in-place diaphragm which will take the compressive action at the joint, and instead, there is only a link slab joining the girder ends. The deck over the joint is cast in place and there is no cold joint to model. However, the cracking within the link slab was found to play an important role in the tension force that can develop

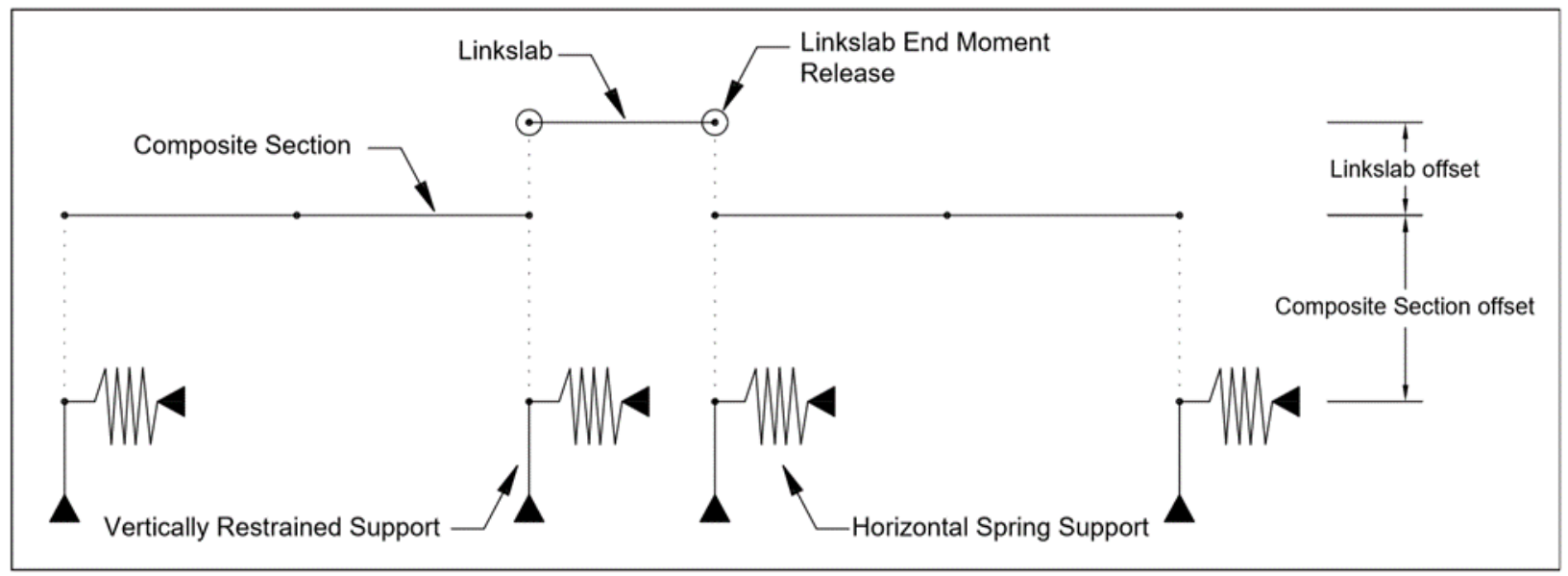

Fig. 1 Finite element model of a two-span link slab element 


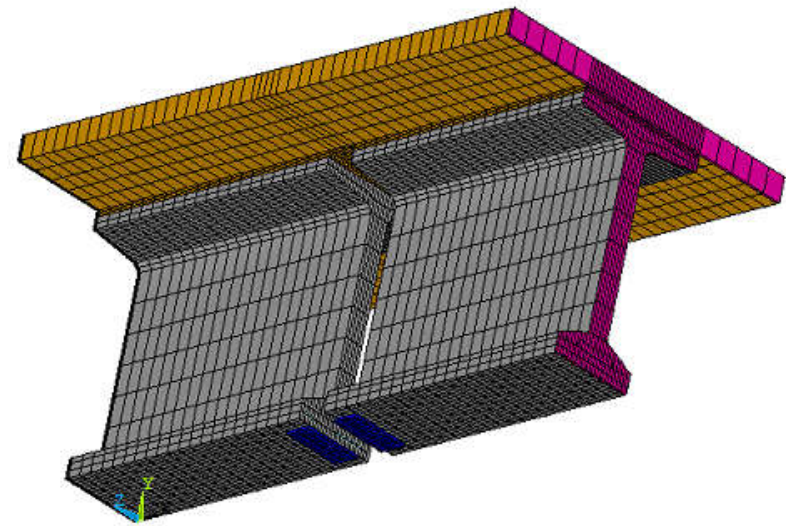

Fig. 2 Link slab model

on the link slab and consequently on the bearing pad supports.

Using the commercially available software ANSYS [20], an element type was selected from among its library that could model the concrete within the section appropriately (see Fig. 2 and 3).

Element SOLID65 is an eight-node three-dimensional solid element with six translational degrees of freedom at each node. Additionally, SOLID65 can model the crushing and cracking of concrete which becomes significant when considering the importance that cracking can have in the forces that develop in the link slab. The concrete in both models is modeled using element type SOLID65, both in the girder as well as the deck, link slab, diaphragm, and bearing pads however in each case with its corresponding material properties, which can be found on Table 1 .

As far as the prestressing strands and the reinforcement bars, these are modeled using the LINK8 element. The LINK8 element corresponds to a two-node three-dimensional spar element with three translational degrees of freedom for each node. To add the prestressing force in the strands, an initial strain value considering the effect of the transfer length was used in the analysis. The initial strain was gradually increased in the first four elements to account for the transfer effect [21, 22].

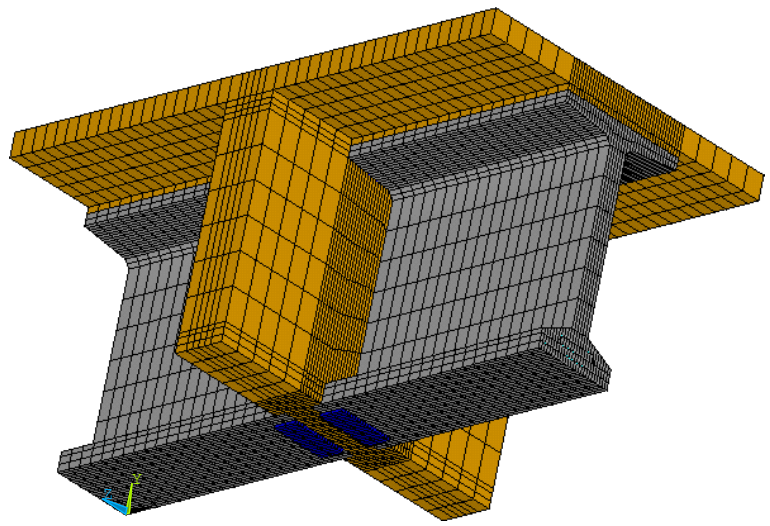

Fig. 3 Continuity diaphragm model
TABLE 1

MATERIAL PROPERTIES

\begin{tabular}{|l|c|c|c|c|}
\hline & $\begin{array}{c}\text { Compressiv } \\
\text { e Strength } \\
(\mathrm{MPa})\end{array}$ & $\begin{array}{c}\text { Modulus of } \\
\text { Elasticity } \\
(\mathrm{MPa})\end{array}$ & $\begin{array}{c}\text { Poisson's } \\
\text { ratio }\end{array}$ & $\begin{array}{c}\text { Unit weight } \\
\left(\mathrm{kN} / \mathrm{m}^{3}\right)\end{array}$ \\
\hline $\begin{array}{l}\text { Deck and } \\
\text { diaphragm } \\
\text { concrete }\end{array}$ & 44.82 & $3.168 \times 10^{4}$ & 0.20 & 23.56 \\
\hline $\begin{array}{l}\text { Girder } \\
\text { Concrete }\end{array}$ & 79.29 & $4.214 \times 10^{4}$ & 0.20 & 23.56 \\
\hline
\end{tabular}

An important difference between the two models compared in this work is the presence of the CONTA178 element from the ANSYS library within the continuity diaphragm model. The CONTA178 element is a zero size twonode element with three translational degrees of freedom at each node. The objective of this element is to model the contact and sliding between two adjacent surfaces of other ANSYS objects. CONTA178 is used to model the friction that takes place in the cold joint that exists between the diaphragm and the girder ends, and therefore does not exist in the link slab model. In the diaphragm model, the diaphragm and the girders were modeled separately, and later moved together. This meant there was a pair of duplicate nodes at each point in the contact between these elements. CONTA178 was used between these node pairs.

Another notable difference is the presence of the hairpin bars in the continuity diaphragm model. These were modeled using cylindrical shaped volumes overlapped with the rectangular shaped volume. The link slab model required only the additional modeling of the prestressed strands, including the normal reinforcement only within the link slab, and not within the girders.

The meshing for the link slab model was achieved through mapped meshing of all bodies when the geometry had been assembled. The diaphragm model required free meshing in parts where the complexity of the geometry did not allow for mapped meshing to be executed.

\section{MODEL LOADING}

This study focuses on comparing the force transfer mechanism from a joint with a cast-in-place continuity diaphragm with positive reinforcement, with the force transfer mechanism from a joint with a link slab.

Specifically, the stress condition that was analysed is the one that results from temperature gradient loading. For the case with the link slab, the loading was applied based on the displacements the model's free ends would be subjected to under temperature gradient load. In order to avoid stress concentrations around the loading points, a rigid face was applied at either girder end. The rigid face was meshed along with the rest of the model but was only 1 -in. thick and was defined using a material with a modulus of elasticity 10,000 times higher than concrete.

Vertical and horizontal displacements were then applied to the nodes of this face based on results from temperature gradient loading on the line model developed for a previous 
parametric study and long-term field data analysis and which is shown in Fig. 1.

The line model was used in validating results from both a parametric study, as well as a long-term field study in a prestressed concrete bridge as part of a performance study of link slab continuity [23].

\section{RESULTS}

The results from the analysis of the link slab and the continuity diaphragm models were compared. The distribution of stress in both models occurs differently. For the case of the link slab model the main resistance to displacement comes from both the bearing pads and the link slab. In the continuity diaphragm model the resistance comes from multiple parts which also include the bearing pads and the deck, however the presence of the continuity diaphragm makes the stress distribution happen completely different.

The only restraint to girder end rotation in the link slab model comes from the bearing pads and the deck. This gives the girder ends much more freedom to rotate, as the stiffness of the bearing pads, by comparison to the stiffness of a continuity diaphragm, is quite low.

In this regard, it can be observed that the higher girder end rotation is also reflected upon the low contribution of this detailing towards continuity, as was concluded in a parametric study within a prior work[23].

The continuity diaphragm model imposes a higher restraint to girder end rotation.

The existence of the continuity diaphragm ensures the compatibility conditions between both girder ends and provides a higher level of continuity by comparison with a link slab. The deformed shape of the continuity diaphragm model presents a much more continuous deformation profile than could be observed in the link slab model.

The higher continuity level provided by the continuity diaphragm implies a better distribution of stress, resulting in less stress concentration within all involved parts, as will be observed later in this study.

Bearing Pad Deformation

The bearing pads in both models have different roles. In the case of the link slab model, the bearing pads are restricting displacement of the girder bottom along with the link slab. The bearing pads are placed in the ideal position to restrict displacements of the girder end, however, the material which they are made from is much softer than concrete and therefore allows for much greater displacement as can be seen in Fig. 4 .

When viewing the $x$-component of the elastic strain on the bearing pads for the link slab model, and comparing them with the results from the continuity diaphragm model, it can be observed that the elastic strain in the bearing pads is much lower with the presence of a continuity diaphragm, as can be seen in Fig. 5. The positive reinforcement in the continuity diaphragm is especially effective in bridging the compatibility of displacements on the girder bottom, this relieves the bearing pads from having to supply the restriction toward girder end rotation in this location.
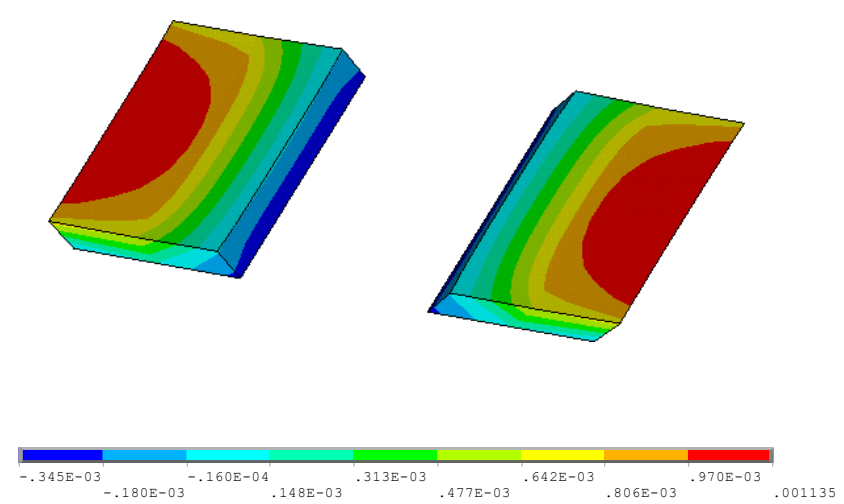

Fig. 4 X-component elastic strain on the bearing pads - link slab model

As can be seen in Fig.5, the magnitude of the $x$ component of the elastic strain in the bearing pads of the continuity diaphragm model is much lower than the magnitude for the same parameter in the link slab model. The overall influence of the bearing pads towards joint performance is, therefore, also much smaller in the continuity diaphragm model.

The equivalent stress in the bearing pads in the link slab model can be seen in Fig. 6, which reveals that substantially higher stresses develop in comparison with the case for the continuity diaphragm model, Fig. 7.

The difference between the stress values in the bearing pads for both models stems from the difference in the roles the bearing pads play for the structural system. In the link slab model, the bearing pads are the only restricting force at the girder bottom, whereas in the continuity diaphragm, there are hairpin bars that are taking this precise purpose.

The displacements on $\mathrm{X}$ reflect the previous observation.

Fig. 8 shows the displacement on $\mathrm{X}$ on the bearing pads in the link slab model. When these displacements are compared with the displacements shown in Fig. 9, from the continuity diaphragm model, it can be observed that there is a drastic difference in the magnitude of results.
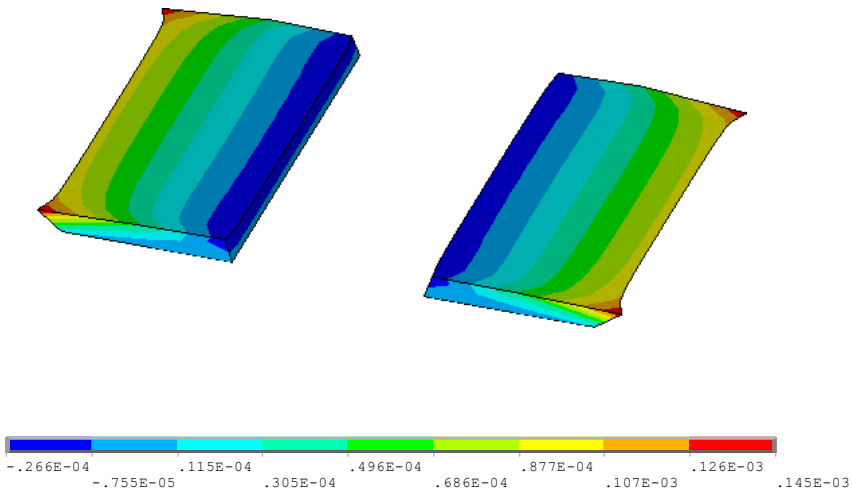

Fig. $5 \mathrm{X}$-component elastic strain on the bearing pads continuity diaphragm model 

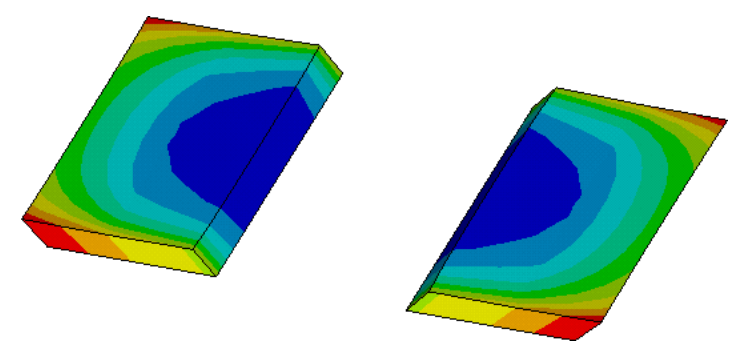

$24.90625 .317^{25.728} 26.139^{24.688} 2^{26.960^{27.372}} 27.782^{28.193} 28.604$

Fig. 6 Equivalent stress contour on the bearing pads - link slab model $(\mathrm{MPa})$

The bearing pads in the link slab model have displacements that are of much higher magnitude than is the case for the continuity diaphragm.

The higher degree of continuity from the diaphragm with positive reinforcement is reflected on the lower impact the joint has on the bearing pads when it comes to the effects from temperature gradient.

Link Slab Contribution vs Continuity Diaphragm Contribution

Both models discussed in this study represent different continuity conditions, as well as different degrees of continuity. The nature of the continuity at the joint will be reflected on the stress and strain distribution within the different parts of each structural system.

Axial stress in the deck

Though the decks remain continuous in both models, the role they play is different. In the case of the link slab model, the deck or link slab, will be the sole point of union between the girder ends. This means the link slab and its stiffness are the only means by which the joint can compatibilize girder end rotations (see Fig. 10).

The importance of the link slab's role in the system's degree of continuity becomes apparent when the stress on the link slab is viewed more carefully.
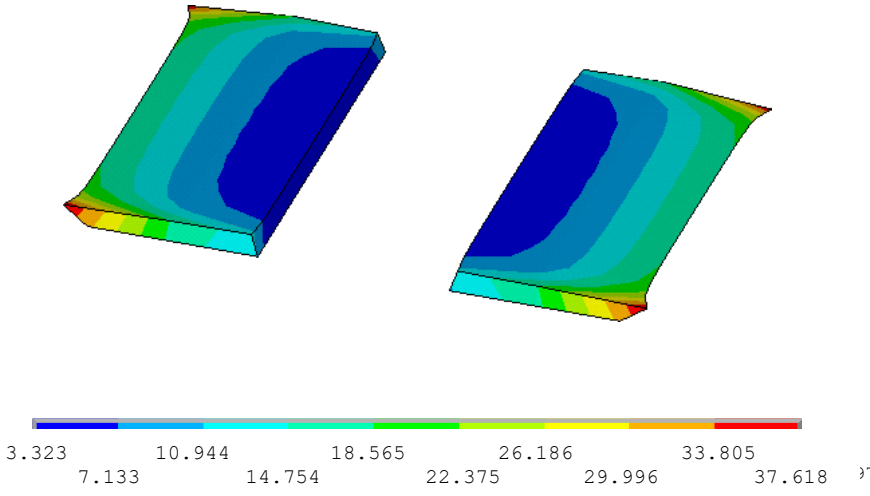

Fig. 7 Equivalent stress contour on the bearing pads continuity diaphragm model (MPa)
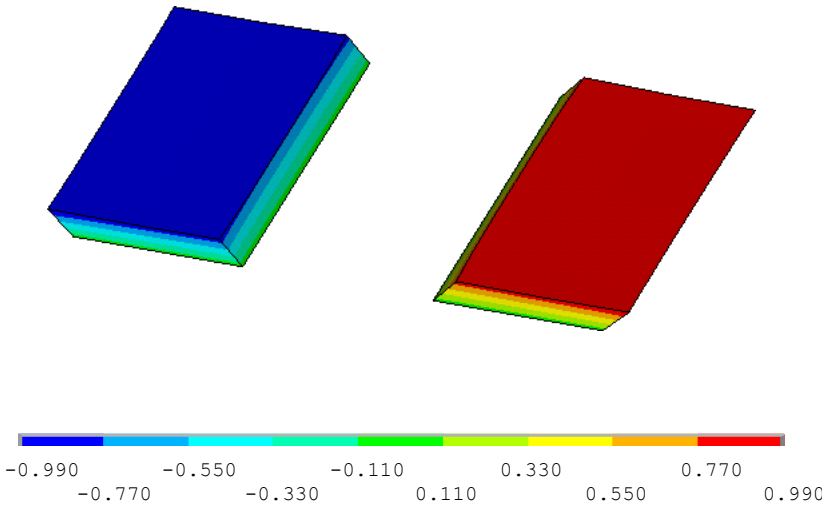

Fig. 8 Displacement on $\mathrm{X}$ at the bearing pads - link slab model (mm)

The values of axial stress are much higher and more concentrated in the link slab model, Fig. 10, than in the continuity diaphragm model, Fig. 11.

Within the continuity diaphragm model, the deck will not have the main role of compatibilizing girder end rotations. It will be the place of the continuity diaphragm to provide the means for continuity to be established and therefore the deck's role becomes secondary in this type of joint.

The deck's secondary role in establishing continuity becomes apparent when the results for axial stress concentration is analysed. In both models we find that while the decks are being subjected to the effects of temperature gradient, there is mostly compression stress in the deck. Its important to note however, that the stress is far more concentrated and elevated in the link slab model.

Stress distribution in the link slab

When the equivalent stress distribution is analysed, a similar observation can be made as in the case for axial stress. The deck in the link slab model is having stress values that are much higher than is the case for the continuity diaphragm.

Fig. 12 shows the equivalent stress distribution in the deck within the link slab joint.
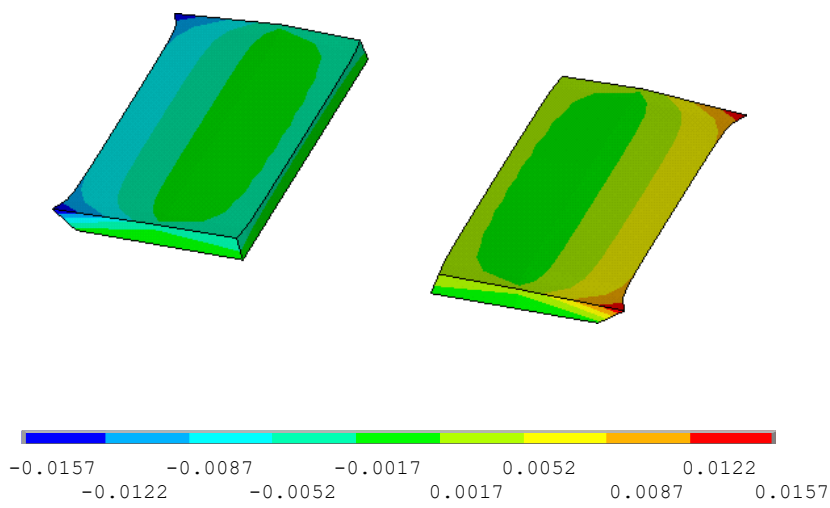

Fig. 9 Displacement on $\mathrm{X}$ at the bearing pads - continuity diaphragm model (mm) 


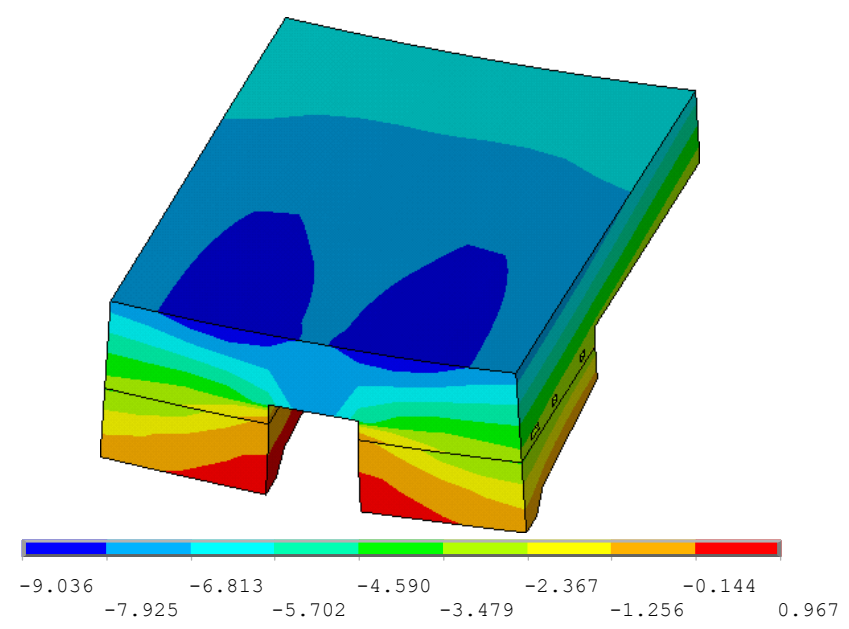

Fig. 10 Axial stress on the deck at the continuity - Link slab model (MPa)

As can be observed by comparing this with Fig. 10, axial stress is the most predominant type of stress within this type of joint. Fig. 13 shows the stress distribution with a continuity diaphragm.

When the results for the continuity diaphragm model are compared with the link slab model, it can be observed that the stress values are much lower and much more distributed in the continuity diaphragm model, and much more concentrated in the link slab model.

\section{Stress distribution at the girder ends}

The impact of the degree of continuity affects stress distributions in the girder ends strongly. In the case of the link slab model, axial stress becomes concentrated on the deck and the bearing pads. The girder end sees a stress distribution surrounding these focal points as can be observed in Fig. 14.
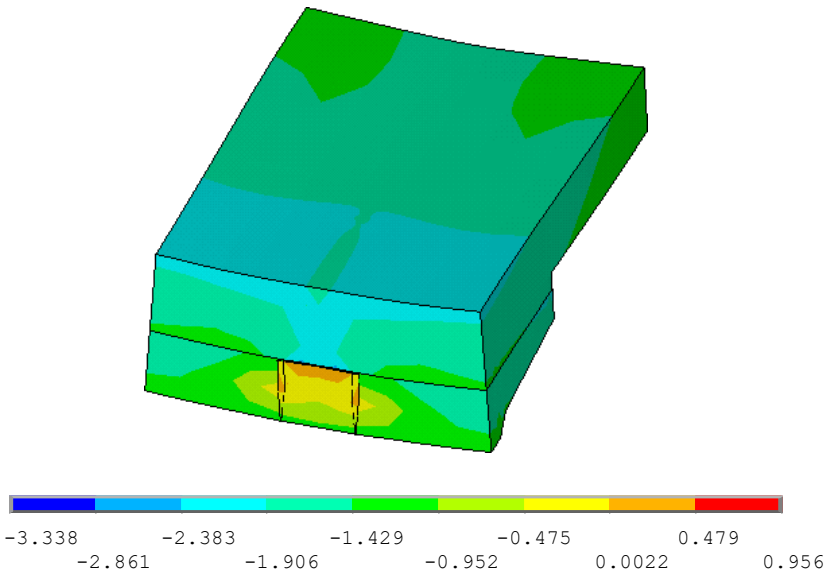

Fig. 11 Axial stress on the deck at the continuity - Continuity diaphragm model (MPa)

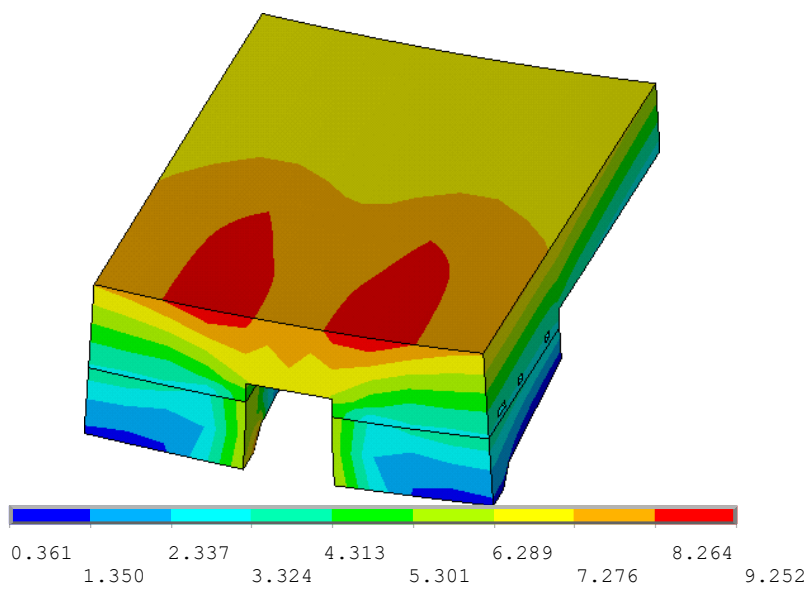

Fig. 12 Equivalent stress distribution in the deck - link slab model (MPa)

Stress is much more concentrated in the link slab model, than in the continuity diaphragm model. Fig. 15 shows the axial stress distribution in the continuity diaphragm model.

As can be observed on Fig. 15, the axial stress is much more distributed in the continuity diaphragm model. The compatibility condition provided by the positive reinforcement in this case, grants the conditions for axial stress to be distributed on the entire girder end more evenly.

Equivalent stress distributions reflect the previous observations on axial stress. Stress is much more concentrated in the link slab model, Fig. 16, than in the continuity diaphragm model, Fig. 17.

In both these figures it also becomes apparent that axial stress is the main contributor in the equivalent stress for both models.
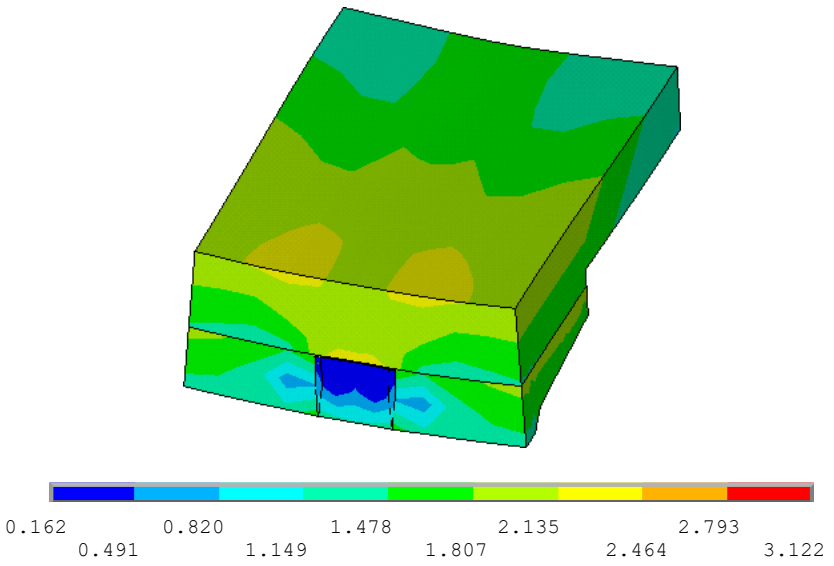

Fig. 13 Equivalent stress distribution in the deck - Continuity diaphragm model (MPa) 


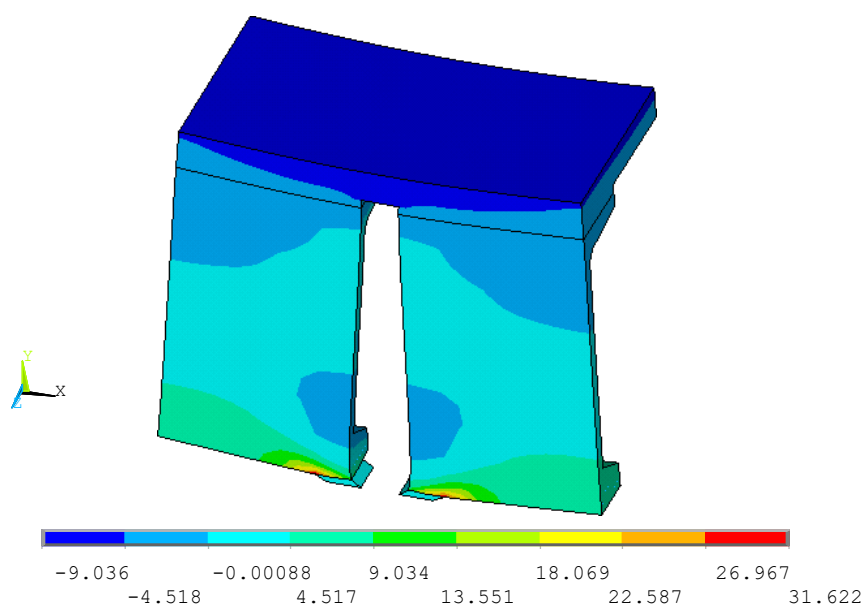

Fig. 14 Axial stress distribution at the girder ends - link slab model $(\mathrm{MPa})$

\section{CONCLUSIONS}

Based on results from this study, the following conclusions can be drawn:

\section{Bearing Pads}

Bearing pad performance is closely linked to the nature of the continuity at the joint. In the case of the link slab model, where continuity is partial, the bearing pads take up an important role as they become responsible for restricting the displacement of the bottom portion of the girder ends. Concentrated stress on the bearing pads in the link slab model is much higher by comparison with the continuity diaphragm model.

In the continuity diaphragm model, stress is much lower on the bearing pads. The overall displacement and deformation of the bearing pads is also much lower than it is in the link slab model. The difference in how the bearing pads will be affected is directly related to the bearing pads role within the established continuity.

In a partially continuous joint where a link slab is present as the main structural element providing continuity, the bearing pads will be placed under much higher stress and as such, the properties of the bearing pad will be much more influential toward the performance of the continuity.

The highest recorded axial displacement in the Link Slab Model at the bearing pads was approximately 60 times larger than the highest recorded axial displacement in the Continuity Diaphragm Model.

In a fully continuous joint where there is positive reinforcement, the influence of the bearing pads on the structural behavior of the system becomes less important and as such, there are much lower demands placed on them by comparison to their role in link slab joint.
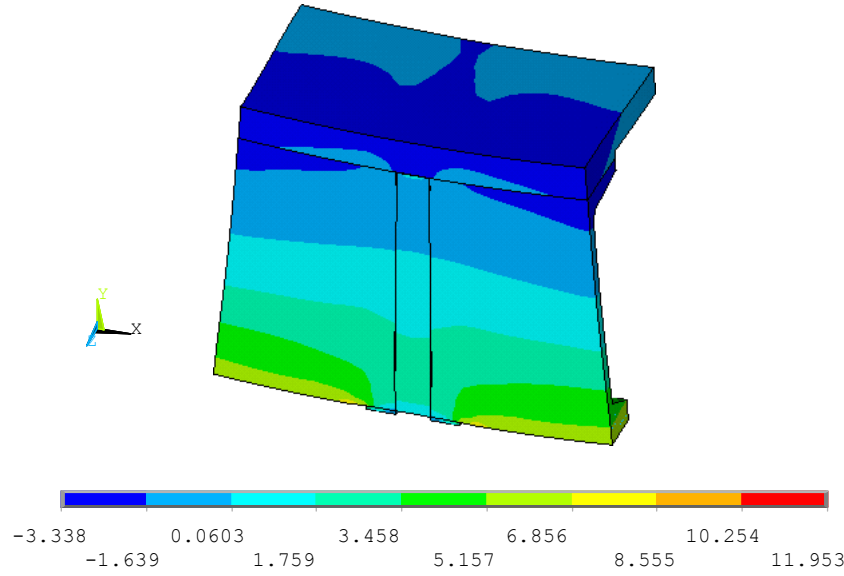

Fig. 15 Axial stress distribution at the girder ends - Continuity diaphragm model (MPa)

Deck

Deck performance, or link slab performance, within a joint with continuity is highly dependent on the nature of the continuity. Joints where the link slab is the main source of continuity will have a much higher stress concentration at the girder top, and in the area surrounding the deck than is the case for joints with a continuity diaphragm with positive reinforcement. Not only will there be a difference in the magnitudes, but in the overall pattern for stress concentration. Link slab continuity will see higher stress concentrations for load cases where a continuity diaphragm will produce lower stress, such as is the case for temperature gradient. This is due to the placement of the restrictions to girder end deformation.

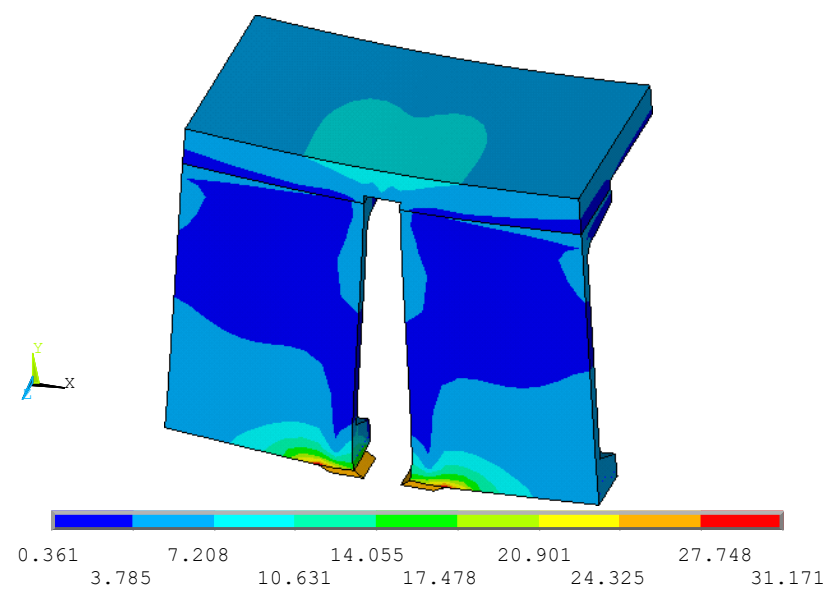

Fig. 16 Equivalent stress distribution at the girder ends - link slab model $(\mathrm{MPa})$ 


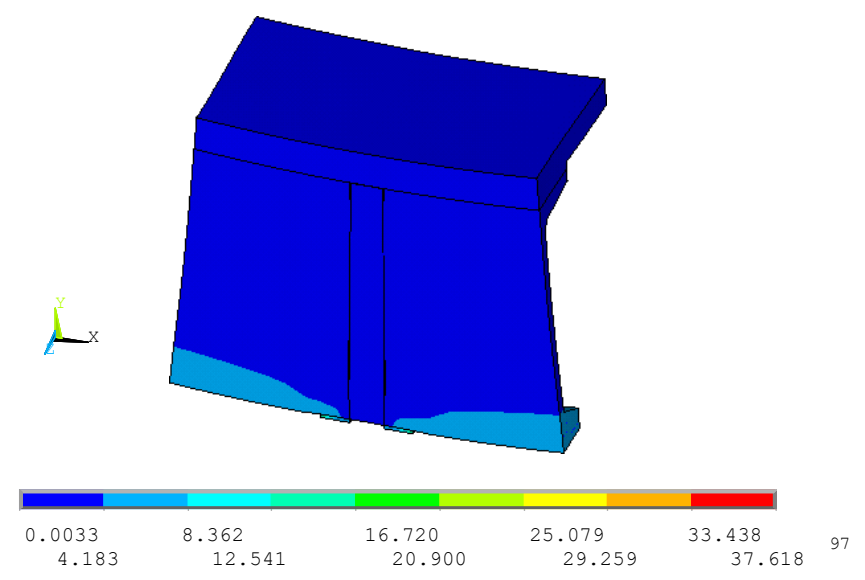

Fig. 17 Equivalent stress distribution at the girder ends Continuity diaphragm model (MPa)

In a link slab joint, the partial continuity is provided mainly by the link slab and balanced with the bearing pads. Within a joint with a continuity diaphragm with positive reinforcement, most of the continuity is provided by the diaphragm itself, relying much less on the bearing pads and deck. Given the much lower stiffness of the bearing pads when compared to the stiffness of the hairpin bars of the positive reinforcement, the resistance provided is much lower, and therefore allows for much larger displacement of the girder ends in a joint with partial continuity.

The deck in a joint with a continuity diaphragm with positive reinforcement will have much lower stress concentrations; the stress distribution will also be of a different nature. Considering the continuity diaphragm is doing most of the restriction on the girder ends, for the case of temperature gradient, the deck will be subjected mostly to compressive stress; though the type of stress that occurs in a joint with a link slab continuity will be similar, the magnitudes of such stress and its distribution will be different.

As the deck's role in providing continuity becomes less protagonist, the stress concentration in the deck will be lower.

\section{ACKNOWLEDGMENT}

The authors gratefully acknowledge the financial support provided by the Louisiana Transportation Research Center (LTRC) (LTRC Project No. 14-1ST) and the Louisiana Department of Transportation and Development (DOTD). Any opinions, findings, and conclusions or recommendations expressed in this material are those of the authors and do not necessarily reflect the views of the sponsoring agencies. 
[12] T. Hossain, A. Okeil, and C. S. Cai, "Field Test and Finite-Element Modeling of a Three-Span Continuous-Girder Bridge," JOURNAL OF PERFORMANCE OF CONSTRUCTED FACILITIES, vol. 28,

\section{REFERENCES}

[1] F. Gastal and P. Zia, "Analysis of Bridge Beams with Jointless Decks," in International Association for Bridge and Structural Engineering (IABSE) Symposium, Lisbon, Portugal, 1989, pp. 555560 .

[2] D. R. Richardson, "Simplified Design Procedures for the Removal of Expansion Joints from Bridges Using Partially Debonded Continuous Decks," Masters Degree, Civil Engineering, North Carolina State University, 1989.

[3] A. ElSafty, "Analysis of Jointless Bridge Decks with Partially Debonded Simple Span Beams," PhD, North Carolina State University, 1994.

[4] P. Zia, C. A., and A. ElSafty, "Jointless Bridge Decks," Center for Transportation Engineering Studies, Rep. No. Research Report No. FHWA/NC/95-006, 1995.

[5] H. K. Thippeswamy and H. V. S. GangaRao, "Analysis of InService Jointless Bridges," TRANSPORTATION RESEARCH RECORD, vol. 1476, pp. 162-170, 1995.

[6] H. K. Thippeswamy, H. V. S. GangaRao, and J. M. Franco, "Performance Evaluation of Jointless Bridges," Journal of Bridge Engineering, Article vol. 7, no. 5, p. 276, 2002.

[7] A. M. Okeil and A. ElSafty, "Partial Continuity in Bridge Girders with Jointless Decks," Practice Periodical on Structural Design \& Construction, Article vol. 10, no. 4, pp. 229-238, 11// 2005.

[8] R. N. Mothe, Partial continuity in prestressed concrete girder bridges with jointless decks. [electronic resource] ([Thesis / Louisiana State University: 2006]). [Baton Rouge, La. : Louisiana State University, 2006], 2006.

[9] A. El-Safty and A. Okeil, "Extending the service life of bridges using continuous decks," PCI JOURNAL, vol. 53, no. 6, pp. 96$111,2008$.

[10] A. M. Okeil, S. C. S. Cai, V. Chebole, and T. Hossain, "Evaluation of continuity detail for precast prestressed girders," Louisiana State University. Dept. of Civil and Environmental Engineering, Baton Rouge, Louisiana, 2011.

[11] A. Okeil, T. Hossain, and C. S. Cai, "Field monitoring of positive moment continuity detail in a skewed prestressed concrete bulb-tee girder bridge," PCI JOURNAL, pp. 80-90, 2013.
[13] T. Hossain, A. M. Okeil, and C. S. Cai, "Calibrated Finite Element Modeling of Creep Behavior of Prestressed Concrete Bridge Girders," ACI STRUCTURAL JOURNAL, vol. 111, no. 6, pp. 1287-1296, 2014

[14] A. Okeil and M. Canales, "Evaluating Louisiana New Continuity Detail for Girder Bridges," Louisiana Transportation Research Center, Baton Rouge, Louisiana, 2019.

[15] T. Hossain and A. Okeil, "Force transfer mechanism in positive moment continuity details for prestressed concrete girder bridges," COMPUTERS AND CONCRETE, vol. 14, no. 2, pp. 109-125, 2014.

[16] M. Hastak, A. Mirmiran, R. A. Miller, R. Shah, and R. Castrodale, "State of Practice for Positive Moment Connections in Prestressed Concrete Girders Made Continuous," JOURNAL OF BRIDGE ENGINEERING, vol. 8, no. 5, pp. 267-272, 2003.

[17] R. A. Miller, R. Castrodale, A. Mirmiran, and M. Hastak, "Connection of Simple Span Precast Concrete Girders for Continuity," in "Rep. No. NCHRP Report 519," Transportation Research Board, Washington, D.C., 2004.

[18] AASHTO, AASHTO LRFD bridge design specifications, customary U.S. units. [electronic resource]. Washington, DC American Association of State Highway and Transportation Officials, 2012.

[19] T. Hossain, Global and local performance of prestressed girder bridges with positive moment continuity detail. [electronic resource] (([Dissertation / Louisiana State University: 2012])). [Baton Rouge, La. : Louisiana State University, 2012], 2012.

[20] ANSYS. (2008, 01/15/2019). Theory Reference

[21] E. G. Nawy, Prestressed Concrete A Fundamental Approach. 2000.

[22] J. C. Domingo and C. Kuang-Han, "Stress-Strain Relationship for Reinforced Concrete in Tension," Journal Proceedings, vol. 83, no. $1,1 / 1 / 19861986$.

[23] M. Canales, "Performance Study of Link Slab Continuity in Prestressed Concrete Bridges," Louisiana State University, Dissertation, May 2019, 2019. 